\title{
Peri-implantitis and periodontitis: Use of bacteriological test in dental practice
}

\author{
Francesco Carinci $^{1,2^{\star}}$, Rosa Maria Gaudio ${ }^{3}$ \\ ${ }^{1}$ Department of Morphology, Surgery and Experimental Medicine, University of Ferrara, Ferrara, Italy; \\ *Corresponding Author: crc@unife.it \\ ${ }^{2}$ Department of Law, University of San Marino, Montegiardino, Republic of San Marino \\ ${ }^{3}$ Department of Medical Sciences, University of Ferrara, Ferrara, Italy
}

Received 15 April 2013; revised 17 May 2013; accepted 24 May 2013

Copyright (C) 2013 Francesco Carinci, Rosa Maria Gaudio. This is an open access article distributed under the Creative Commons Attribution License, which permits unrestricted use, distribution, and reproduction in any medium, provided the original work is properly cited.

\begin{abstract}
Peri-implantitis has been defined as an inflamematory condition involving dental implants, surrounding mucosa and bone, which lose supporting bone. Although high success rates for endosseous implants have been reported, failures occur, and some implants are lost or removed. At least $10 \%$ of the failures have been suggested to be the result of peri-implantitis. One of the major causes of the peri-implantitis is the bacterial colonization of implant surfaces but additional risk factors such as periodontitis, poor oral hygiene, tobacco consumption, prepost operative therapies and genetic susceptibility should be considered. In the present study a real-time PCR bases assay was designed to detect and quantify red complex species, then used to investigate 307 periodontal pocket samples from 127 periodontitis patients and 180 controls. Results demonstrated a significant higher prevalence of red complex species and increased amount of Porphyromonas gingivalis and Treponema denticola in periodontal pocket of periodontitis. Since a higher risk of peri-implantitis occurs in periodontally affected patients, detection and treatment of bacteria is a fundamental objective to ensure dental implant survival.
\end{abstract}

Keywords: Peri-Implantitis; Periodontitis; Microbia; Bacterial Test; Genetic Test

\section{INTRODUCTION}

Dental implant plays an important role in restorative dentistry. However, the long term implant's stability depends on the integration between fixtures and the surrounding bone. Microbia presented in the oral cavity has a substantial impact on biofilm formation on newly placed implants. Since periodontally compromised patients have a higher risk of peri-implantitis than unaffected patients, a transmission of periodontal pathogens from periodontal sites to implants is possible [1]. Periimplantitis is an inflammatory condition of mucosa and surrounding bone. Although high success rates for endosseous implants have been reported, failures occasionally occur, and implants are lost or must be removed. Peri-implantitis causes at least $10 \%$ of fixture failures. The most evident clinical signs of peri-implantitis are hyperplasia of the soft tissue, suppuration, gradual bone loss and progressive mobility of the implant. One of the causes of the peri-implantitis is the bacterial colonization of implant surfaces. Considering peri-implantitis means consider risk factors such as periodontitis, poor oral hygiene, tobacco consumption, pre-post operative therapies and genetic susceptibility [2].

Some authors [3] studied the possible association between a previous history of periodontitis and peri-implantitis, and indicated that subjects with a history of periodontitis might be at greater risk for peri-implant infections.

Other authors [4] evaluated the prevalence of peri-implant diseases around implants and the possible relationship with periodontal bone loss, systemic condition, and demographic profile. Presence of peri-implant diseases may be associated with generalized periodontal bone loss and with poor oral hygiene [5].

Since bacteria are the main cause of periodontitis and peri-implantitis, some methods have been used for microbiological testing in periodontitis [6]. However, many techniques have not been fully accepted due to low 
sensitivity or specificity, moreover sometimes they are slow, expensive and laborious. Polymerase chain reaction (PCR) test is rapid and sensitive especially if few but high sensitive bacteria are investigated such as Porphyromonas gingivalis, Tannerella forsythia, and Treponema denticola (i.e. red complex bacteria).

Bacterial species involved in the initiation and progression of periodontal disease were classified by Socransky in several groups of bacteria labeled by colors. The categories were based upon the pathogenicity of the bacteria and their role in the development of plaque. The red complex showed the strongest relationship with the clinical parameters considered most meaningful in severe forms of periodontal disease [7].

Both $P$. gingivalis and T. denticola occur concomitantly with the clinical signs of periodontal destruction. They are considered the first pathogens involved in the clinical destruction of periodontal tissues. Moreover both them and T. forsythia, show a higher prevalence in disease than in health suggesting that these bacterial are associated with the local development of periodontitis and peri-implantitis [8].

In the present report we investigate a wide cohort of patient to verify the effectiveness of PCR based test to be used in dental practice to detect pathogens.

\section{MATERIAL AND METHODS}

A total of 307 individuals participated in the study, 127 were affected by chronic periodontitis, while 180 constituted the control group. Controls include 66 healthy individuals and 114 affected by a moderate gingivitis. Ta- ble 1 summarizes principal characteristics of the two groups.

A sample of the periodontal pocket microbiota was obtained from a single site by a paper probe. DNA was extracted and purified using standard protocols that include two consecutive incubation with lysozyme and proteinase $\mathrm{K}$, followed by spin-column purification.

\subsection{Real-Time Polymerase Chain Reaction}

Primers and probes oligonucleotides were designed basing on 16S rRNA gene sequences of the Human Oral Microbiome Database (HOMD 16S rRNA RefSeq Version 10.1) counting 845 entries. All the sequences were aligned in order to find either consensus sequence or less conservate spots. Two real-time polymerase chain reaction (PCR) runs were performed for each sample. The first reaction quantified the total amount of bacteria using two degenerate primers and a single probe matching a highly conservated sequence of the $16 \mathrm{~S}$ ribosomal RNA gene. The second reaction detected and quantified the three red complex bacteria, i.e. P. gingivalis, T. forsythia and T. denticola, in a multiplex PCR. This reaction included a total of six primers and three probes that were highly specific for each species (see Table 2). Oligonucleotide concentrations and PCR conditions were optimized to ensure sensitivity, specificity and no inhibitions in case of unbalanced target amounts. Absolute quantification assays were performed using the Applied Biosystems 7500 Sequence Detection System. The amplification profile was initiated by a 10 -min incubation period at $95^{\circ} \mathrm{C}$ to activate polymerase, followed by a two-step

Table 1. Sample study.

\begin{tabular}{ccccc}
\hline Sample study features & totals & health & gingivitis & periodontitis \\
\hline subjects (n) & 307 & 66 & 114 & 127 \\
male (n) & 124 & 26 & 42 & 56 \\
female (n) & 183 & 40 & 72 & 71 \\
age (mean years $\pm \mathrm{SD}$ ) & $39.8 \pm 18.9$ & $31.6 \pm 18.6$ & $34.3 \pm 15.4$ & $48.9 \pm 18.2$ \\
sampling depth $(\mathrm{mm} \pm \mathrm{SD})$ & $3.9 \pm 1.7$ & $2.6 \pm 0.6$ & $3.2 \pm 1.0$ & $5.0 \pm 1.7$ \\
\hline
\end{tabular}

Table 2. Primer and probe sequences for the amplification of red complex bacteria.

\begin{tabular}{|c|c|c|}
\hline Bacteria & Primer sequences $\left(5^{\prime}-3^{\prime}\right)$ & Probe sequence $\left(5^{\prime}-3^{\prime}\right)$ \\
\hline Porphyromonas gingivalis & $\begin{array}{c}\text { F-CGCGTGAAGGAAGACAGTCC } \\
\text { R-CGATGCTTATTCTTACGGTACATTC }\end{array}$ & TACGGGAATAACGGGCGATACGAGTATTG \\
\hline Tannerella forsythia & $\begin{array}{c}\text { F-CAGCGATGGTAGCAATACCTGTC } \\
\text { R-TTCGCCGGGTTATCCCTC }\end{array}$ & TGAGTAACGCGTATGTAACCTGCCCGC \\
\hline Treponema denticola & $\begin{array}{l}\text { F-AGCTACGGCTCCGCTTCAG } \\
\text { R-GATACCCATCGTTGCCTTGGT }\end{array}$ & AGCTAATGGGACGCGGGCCCAT \\
\hline Bacteria total load & $\begin{array}{l}\text { F-TGGAAGCATGTGGTTTAATTCGA } \\
\text { R-TGCGGGACTTAACCCAACA }\end{array}$ & CACGAGCTGACGACARCCATGCA \\
\hline
\end{tabular}


amplification of $15 \mathrm{~s}$ at $95^{\circ} \mathrm{C}$ and $60 \mathrm{~s}$ at $57^{\circ} \mathrm{C}$ for $40 \mathrm{cy}-$ cles. All these experiments were performed including non-template controls to exclude reagents contamination.

Plasmids containing synthetic DNA target sequences (Eurofin MWG Operon, Ebersberg Germany) were used as standard for the quantitative analysis. Standard curves for each target were constructed in a triplex reaction, by using a mix of the same amount of plasmids, in serial dilutions ranging from 101 to 107 copies. There was a linear relationship between the threshold cycle values plotted against the log of the copy number over the entire range of dilutions (data not shown). The copy numbers for individual plasmid preparations were estimated using the Thermo NanoDrop spectrophotometer.

The absolute quantification of total bacterial genome copies in samples allowed for the calculation of relative amount of red complex species. To prevent samples and polymerase chain reaction contamination, plasmid purification and handling was performed in a separate laboratory with dedicated pipettes.

\subsection{Statistical Analysis}

Descriptive statistics was performed using Microsoft Excel spreadsheets. The Freeman-Halton extension of Fisher's exact test to compute the (two-tailed) probability of obtaining a distribution of values in a $2 \times 3$ contingency table, given the number of observations in each cell. Odds ratio calculation was performed online at the OpenEpi web site (www.openepi.com).

Absolute bacteria amount were normalized against the total bacterial load, obtaining the relative bacteria amount (RBA). The one-way analysis of variance (ANOVA) was used to determine whether there was any significant differences between the mean RBA value of three patients group, i.e. healthy, gingivitis and periodontitis.

\section{RESULTS}

Occurrence and amount of red complex bacteria from crevicular fluid were evaluated in 307 individuals. Prevalence of the three investigated species among health, gingivitis and periodontitis patients was shown in Figure 1. A single specimen from each patient was analyzed by quantitative real time PCR, obtaining measures of total bacteria load and of three species involved in periodontitis, i.e. P. gingivalis, T. forsythia, and T. denticola as reported in Figures 2 and $\mathbf{3}$ produced by LAB s.r.l. (Codigoro, Ferrara, Italy). Here we report a preliminary study focused mainly on prevalence of these three species among groups of patients with different diagnosis-regardless of different clinical aspects that may describe severity of the disease-in order to understand whether the presence of the red complex species and their relative amount may be considered predictive

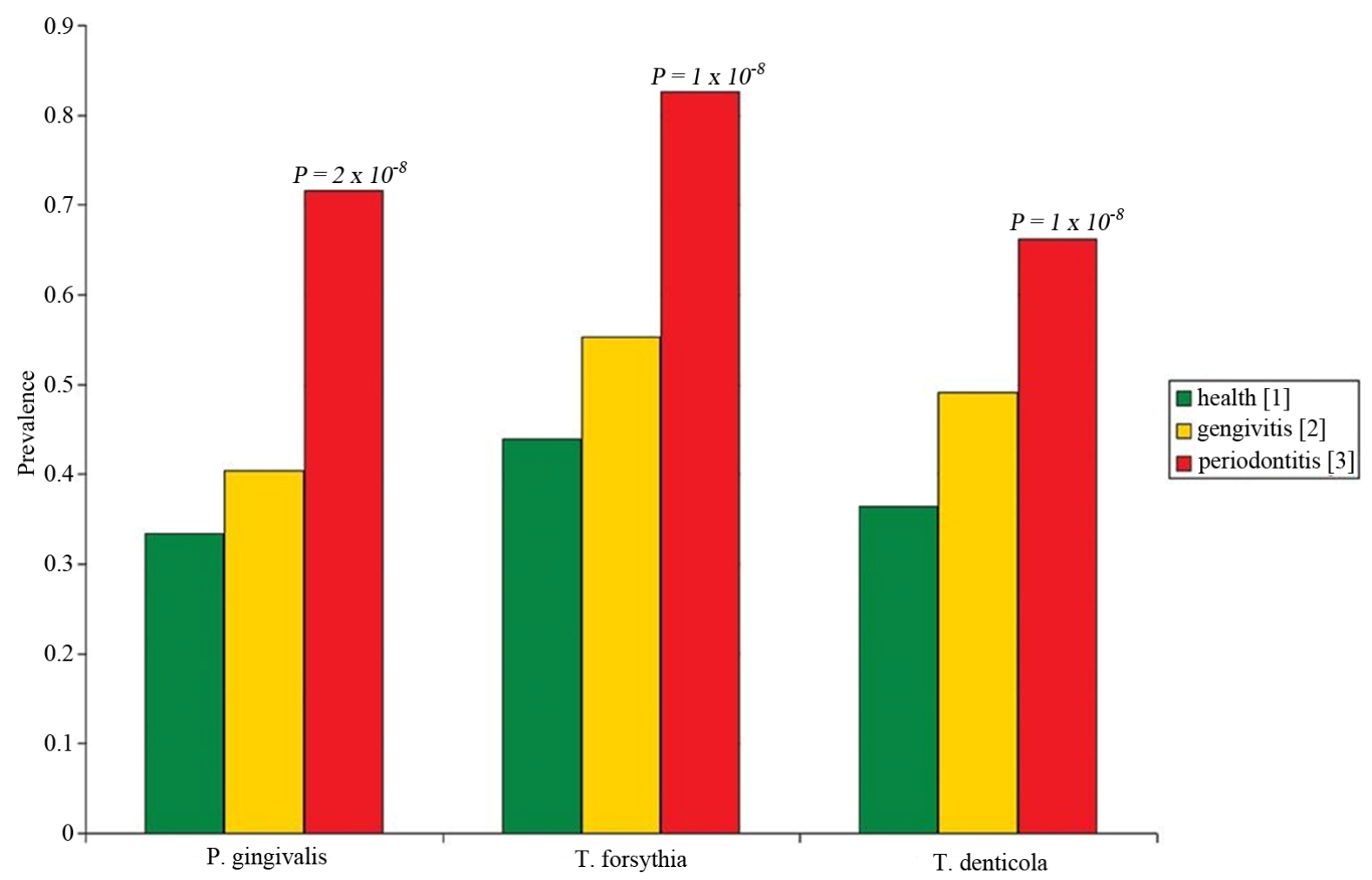

Figuer 1. Prevalence of red complex bacterial species in healthy (green), gingivitis (yellow), and periodontitis (red) patients. 


\section{MICROBIOLOGICAL TEST}

\begin{tabular}{l|l}
\hline Dr. \\
Street addres: \\
CAP and City \\
Phone \\
E-mail & \\
\hline Patient code & \\
\hline Date of birth & \\
\hline sex & \\
\hline site & \\
\hline Depth pocket & \\
\hline Date of sampling & \\
\hline$\square \quad$ Microbiological Test \\
\hline
\end{tabular}

\section{Analysis results}

\begin{tabular}{|c|c|c|c|c|}
\hline BACTERIA & Quantity & $\begin{array}{l}\text { Relative } \\
\text { quantity }\end{array}$ & $\begin{array}{l}\text { range parameters } \\
\text { (basso, medio, alto) }\end{array}$ & $\begin{array}{l}\text { Infection level } \\
\text { (low, medium, } \\
\text { high) }\end{array}$ \\
\hline Porphyromonas gingivalis & 43000 & 0.372 & $\begin{array}{c}\text { low: } 10 \text { copy }<\text { Q.R. }<0.0002 \\
\text { medium: } 0.0002 \leq \text { Q.R. }<0.01 \\
\text { high: } \text { Q.R. } \geq 0.01\end{array}$ & high \\
\hline Tannerella forsythia & 911 & 0.008 & $\begin{array}{c}\text { low: } 10 \text { copy }<\text { Q.R. }<0.0001 \\
\text { medium: } 0.0001 \leq \text { Q.R. }<0.01 \\
\text { high: } \text { Q.R. } \geq 0.01\end{array}$ & medium \\
\hline Treponema denticola & 10000 & 0.086 & $\begin{array}{c}\text { low: } 10 \text { copy }<\text { Q.R. }<0.0001 \\
\text { medium: } 0.0001 \leq \text { Q.R. }<0.005 \\
\text { high: } \text { Q.R. } \geq 0.005\end{array}$ & high \\
\hline Total bacterial load & 115631 & & & \\
\hline
\end{tabular}

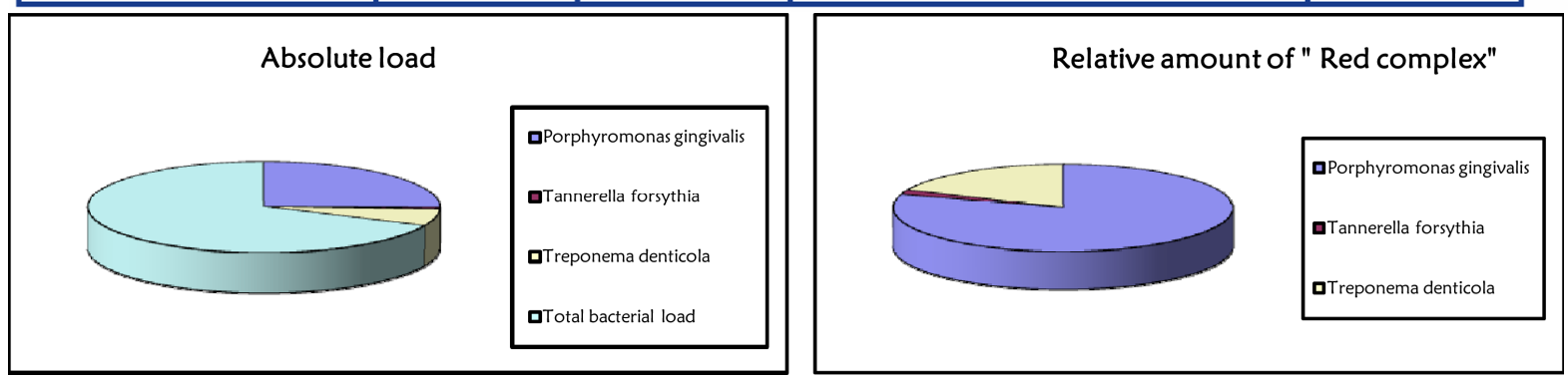

Figure 2. Report of bacterial test. The bacterial load is marked with traffic signals (red, yellow, and green traffic lights correspond to severe, medium or low bacterial load).

factors of periodontitis.

Each specie was common among healthy patients, however, the prevalence was roughly double in periodontitis group. Intermediate values, but closer to healthy 


\section{MICROBIOLOGICAL TEST}

\begin{tabular}{l|l}
\hline Dr. \\
Street addres: \\
CAP and City \\
Phone \\
E-mail & \\
\hline Patient code & \\
\hline Date of birth & \\
\hline sex & \\
\hline site & \\
\hline Depth pocket & \\
\hline Date of sampling & \\
\hline$\square \quad$ Microbiological Test & $\square$ Cenetic test
\end{tabular}

\section{Analysis results}

\begin{tabular}{|c|c|c|c|c|}
\hline BACTERIA & Quantity & Relative quantity & $\begin{array}{l}\text { range parameters } \\
\text { (basso, medio, alto) }\end{array}$ & $\begin{array}{l}\text { Infection level } \\
\text { (low, medium, } \\
\text { high) }\end{array}$ \\
\hline $\begin{array}{c}\text { Porphyromonas } \\
\text { gingivalis }\end{array}$ & 108 & 0.002 & $\begin{array}{c}\text { low: } 10 \text { copy }<\text { Q.R. }<0.0002 \\
\text { medium: } 0.0002 \leq \text { Q.R. }<0.01 \\
\text { high: } \text { Q.R. } \geq 0.01\end{array}$ & medium \\
\hline Tannerella forsythia & 0 & 0.000 & $\begin{array}{c}\text { low: } 10 \text { copy }<\text { Q.R. }<0.0001 \\
\text { medium: } 0.0001 \leq \text { Q.R. }<0.01 \\
\text { high: } \text { Q.R. } \geq 0.01\end{array}$ & low \\
\hline Treponema denticola & 40 & 0.001 & $\begin{array}{c}\text { low: } 10 \text { copy }<\text { Q.R. }<0.0001 \\
\text { medium: } 0.0001 \leq \text { Q.R. }<0.005 \\
\text { high: } \text { Q.R. } \geq 0.005\end{array}$ & medium \\
\hline Total bacterial load & 53408 & & & \\
\hline \multirow{2}{*}{\multicolumn{2}{|c|}{ Absolute load }} & & \multicolumn{2}{|c|}{ Relative amount of "Red complex" } \\
\hline & & $\begin{array}{l}\text { QPorphyromonas gingivalis } \\
\text {-Tannerella forsythia } \\
\text { DTreponema denticola } \\
\text { QTotal bacterial load }\end{array}$ & & $\begin{array}{l}\text { aPorphyromonas gingivalis } \\
\text { QTannerella forsythia } \\
\text { QTreponema denticola }\end{array}$ \\
\hline
\end{tabular}

Figure 3. Bacterial report after peri-implantitis therapies. The lights indicate a reduction in the level of infection (yellow and green traffic lights). 
individuals were observed among patients affected by gingivitis.

Obtained data were detailed in Table 3. The FreemanHalton extension of Fisher's exact test indicated that the prevalence of each red complex specie is different among groups of patients with high degree of statistical significance, $P$. gingivalis $\mathrm{P}$ value $=2 \times 10^{-8}, T$. forsythia $\mathrm{P}$ value $=1 \times 10^{-8}$, and $T$. denticola $\mathrm{P}$ value $=2 \times 10^{-4}$. The higher level of association with periodontitis was observed for $T$. forsythia, indeed the observed odds ratio was $6.1(95 \%$ C.I. 3.1 - 11.9) when healthy individuals were compared to periodontitis patients, and $4.6(95 \%$ C.I. 2.6 - 7.9) when healthy and gingivitis groups where combined and compared to periodontitis patients.

Results of quantitative data indicated that the normalized amount of $P$. gingivalis significantly differs among patient groups $\mathrm{F}(2,304)=7.77$, $\mathrm{P}$ value $=0.001$; as well as for $T$. denticola $\mathrm{F}(2,304)=7.47$, $\mathrm{P}$ value $=0.001$. On the contrary did not vary for $T$. forsythia $F(2,304)=1.41$, $\mathrm{P}$ value $=0.25$.

\section{DISCUSSION}

The polymerase chain reaction (PCR) is the most sensitive and rapid method to detect microbial pathogens in clinical specimens. In particular, the diagnostic value of PCR is significantly higher when specific pathogens that are difficult to culture in vitro or require a long cultivation period such as for anaerobic bacteria species involved in periodontitis onset. A recent improvement of this technique is the real-time PCR that allows for quantification of DNA target using fluorogenic probes in a close setup. Beside the opportunity to quantify target, the advantage to perform the assay is a closed system, in which the reaction tube is never opened after amplification, and is of great value to prevent laboratory contamination and false positive results. In addition the need of a probe in addition to the two PCR primers, further increases the specificity of the reaction.

In the present investigation we designed and tested the performance of a real-time PCR based assay to detect and quantify the red complex bacteria involved in periodontal disease and peri-implantitis. In particular we found that $P$. gingivalis, $T$. forsythia, and T. denticola were strongly related to periodontitis because their prevalence was higher among periodontitis patient. The presence of these bacterial species can significantly increase the risk to develop periodontitis and peri-implantitis, being the OR comprised between 6.1 ( $T$. forsythia) and 3.4 (T. denticola). The results of quantitative data analysis indicated that the relative amount of $P$. gingivalis and T. denticola in periodontal pocket was sensibly higher in affected patients. This indicated that both the presence and relative amount of red complex bacteria is relevant data in periodontal disease diagnosis.

In a workshop of the European Federation on Periodontology [9] about peri-implantitis, a consensus was reached concerning oral peri-implant infections on the basis of the state of the art in the relevant sciences. Important conclusions were that peri-implant mucositis occurs in $80 \%$ of subjects with oral implants, and that peri-implantitis occurs in $28 \%-56 \%$ of subjects studied. Important risk factors for developing peri-implant infections seem to be insufficient oral hygiene, a history of periodontitis and cigarette smoking. Mechanical treatment in combination with antimicrobial oral mouth rinses may be effective in the treatment of mucositis. No evidence has been found that mechanical treatment of peri-implantitis is effective. To control the infection of peri-implantitis, surgical treatment, often in combination with the use of local or systemic antibiotics, is necessary. So it is clear that the parodonto-pathogen bacteria are the main causes of peri-implantitis, and to have a test that allows identifying the main bacteria and bacterial load is a valuable tool in clinical practice.

According with the conclusion of workshop of the European Federation on Periodontology [9], a test that detects the most frequent bacterial species involved in the onset of peri-implantitis (Actinobacillus actinomy cetecomitans, Porphyromonas gengivalis, Tannnerella forsythia, Treponema denticola) [10-12] should be used

Table 3. Association analysis between red complex bacteria and periodontitis.

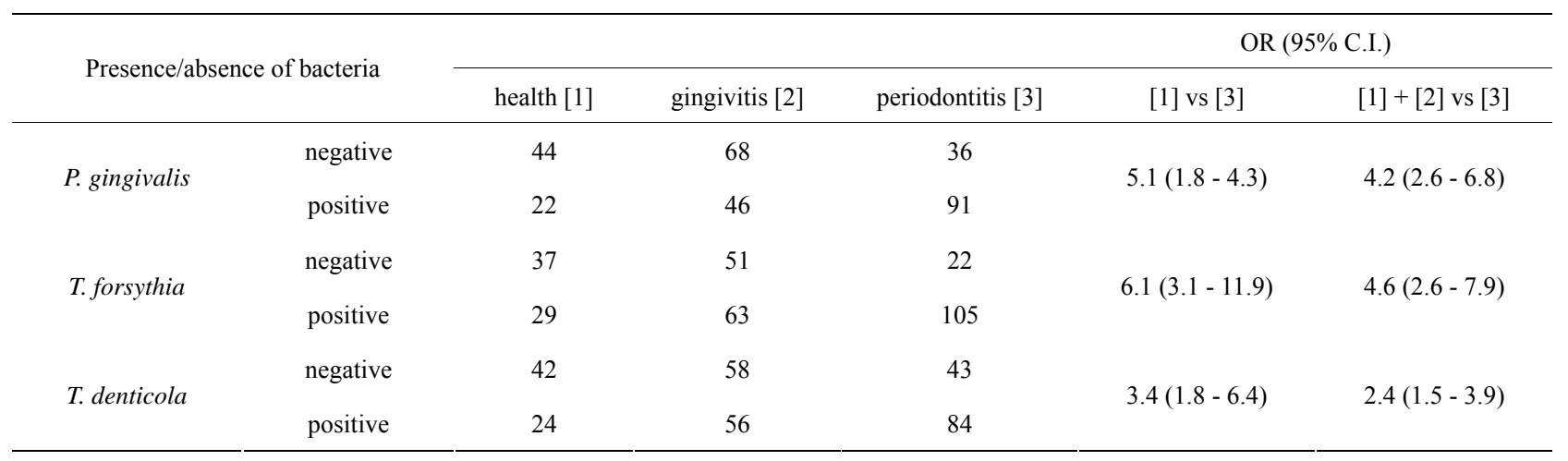


in clinical practice.

Peri-implantitis disease progression depends on the quantity and composition of bacterial flora in peri-implant pockets. A real time PCR test has the following advantages: to identify and quantify of main pathogens in periodontal disease and peri-implantitis; to inform patient about his personal microbiological profile, to make patient knowledgeable about treatment and his compliance in home care; to verify the effectiveness of therapeutic protocols.

\section{CONCLUSION}

Implant failure is one of the main causes of forensic conflict in dentistry. Implantology presents many points of medico-legal concern related to difficulties inherent to surgical and prosthetic procedures and objectives (both functional and aesthetic), as well as full patient collaboration as an essential part of successful treatment [13-15]. An accurate assessment of each case by the clinician is fundamental. The patient should therefore receive complete information and be made fully aware of the risk of treatment failure, as well as possible complications, limits to the procedures, and the fact that successful outcome will also depend on her/his scrupulous observance of the practitioner's instructions and oral care. The aim is to make the patient an active partner in order to obtain a successful treatment. To this end, the use of an extremely detailed information leaflet is strongly advised; after careful clarification of any doubts the patient may have, the patient's written informed consent should be obtained. In this light, monitorization of bacterial status is of paramount importance to ensure the success of implant outcome since the main cause of implant failure is bacterial infection.

\section{REFERENCES}

[1] Heitz-Mayfield, L.J. (2008) Peri-implant diseases: Diagnosis and risk indicators. Journal of Clinical PeriodontalOgy, 35, 292-304. doi:10.1111/j.1600-051X.2008.01275.X

[2] Brunelli, G., Carinci, F., Zollino, I., Candotto, V., Scarano, A. and Lauritano, D. (2012) Peri-implantitis. A case report and literature review. European Journal of Inflammation, 10, 1-6.

[3] Cho-Yan Lee, J., Mattheos, N., Nixon, K.C. and Ivanovski, S. (2012) Residual periodontal pockets are a risk indicator for peri-implantitis in patients treated for periodontitis. Clinical Oral Implants Research, 23, 325-333. doi:10.1111/j.1600-0501.2011.02264.x
[4] Maximo, M.B., de Mendonca, A.C., Alves, J.F., Cortelli, S.C., Peruzzo, D.C. and Duarte, P.M. (2008) Peri-implant diseases may be associated with increased time loading and generalized periodontal bone loss: Preliminary results. The Journal of Oral Implantology, 34, 268-273. doi:10.1563/1548-1336(2008)34[269:PDMBAW]2.0.CO; $\underline{2}$

[5] Serino, G. and Strom, C. (2009) Peri-implantitis in partially edentulous patients: Association with inadequate plaque control. Clinical Oral Implants Research, 20, 169. 174. doi:10.1111/j.1600-0501.2008.01627.x

[6] Loomer, P.M. (2004) Microbiological diagnostic testing in the treatment of periodontal diseases. Periodontology, 34, 49-56. doi:10.1046/j.0906-6713.2002.003424.x

[7] Socransky, S.S., Haffajee, A.D., Cugini, M.A., Smith, C. and Kent Jr., R.L. (1998) Microbial complexes in subgingival plaque. Journal of Clinical Periodontology, 25, 134-144. doi:10.1111/j.1600-051X.1998.tb02419.x

[8] Mineoka, T., Awano, S., Rikimaru, T., Kurata, H., Yoshida, A., Ansai, T., et al. (2008) Site-specific development of periodontal disease is associated with increased levels of Porphyromonas gingivalis, Treponema denticola, and Tannerella forsythia in subgingival plaque. Journal of Periodontology, 79, 670-676. doi:10.1902/jop.2008.070398

[9] Lindhe, J. and Meyle, J. (2008) Peri-implant diseases: Consensus report of the sixth european workshop on periodontology. Journal of Clinical Periodontology, 35, 282-285. doi:10.1111/j.1600-051X.2008.01283.x

[10] Carinci, F., Girardi, A., Palmieri, A., Martinelli, M., Scapoli, L., Avantaggiato, A., et al. (2012) Lab-test 1: Periimplantitis and bacteriological analysis. European Journal of Inflammation, 10, 91-93.

[11] Carinci, F., Girardi, A., Palmieri, A., Martinelli, M., Scapoli, L., Avantaggiato, A., et al. (2012) Lab-test 2: Microflora and periodontal disease. European Journal of Inflammation, 10, 95-98.

[12] Carinci, F., Girardi, A., Palmieri, A., Martinelli, M., Scapoli, L., Avantaggiato, A., et al. (2012) Lab-test 3: Genetic susceptibility in periodontal disease. European Journal of Inflammation, 10, 99-101.

[13] Santoro, V., De Donno, A., Dell'Erba, A. and Introna, F. (2007) Esthetics and implantology: Medico-legal aspects. Minerva Stomatologica, 56, 45-51.

[14] Flanagan, D. (2002) Guidelines for expert testimony in implant dentistry. The Journal of Oral Implantology, 28, 99-100. doi:10.1563/1548-1336(2002)028<0099:GFETII $>2.3 . C O$ ;2

[15] Sykes, D. (2000) Medico-legal aspect of dental implants. Annals of the Royal Australasian College of Dental Surgeons, 15, 309-314. 